\begin{tabular}{lcl}
\hline Bentham OPEN & Open Medicine Journal \\
CrossMark & Content list available at: www.benthamopen.com/MEDJ/ \\
\hline
\end{tabular}

REVIEW ARTICLE

\title{
The Use of Technical Simulation Training in Surgical Education in the United Kingdom
}

\author{
Emma Snashall ${ }^{1}$, Orod Osanlou ${ }^{2}$ and Sandip Hindocha, ${ }^{1, *}$ \\ ${ }^{I}$ Department of Plastic Surgery, Whiston Hospital, Merseyside, L35 5DR, UK \\ ${ }^{2}$ Royal Liverpool University Hospital, Liverpool, Merseyside, L7 8XP, UK
}

Received: July 12, 2015

Revised: September 17, 2016

Accepted: September 17, 2016

\begin{abstract}
Simulation training, where a scenario or setting is replicated, is now firmly associated with surgical training. Involving both technical and non-technical competencies, it provides a valuable tool in training new skills to both new and current surgeons.

As patient safety becomes more of a focus, alongside advances in technology and surgical techniques, there is a continued concern regarding operative exposure for futures surgeons. This void in which simulated training fits, a claim supported by an expanding literature base.
\end{abstract}

The recent integration of simulation into training curricula aims to promote consistency in access to simulation facilities across deaneries and invite the experience of dedicated instructors to optimise educational use.

Keywords: Simulation, Training, Surgery, Education.

\section{AN INTRODUCTION TO SIMULATION TRAINING}

Simulation training refers to an exercise designed to represent a scenario or environment aiming to teach, assess and change behaviours in an individual. Scenarios may be technical, referring to the acquisition of key surgical skills or non-technical and demonstrate other key characteristics of a trainee such as communication or team working.

A surgeon in training must acquire a number of competencies, amongst them a sound knowledge base and the acquisition of core technical skills. Over recent years, there has been increasing interest in the use of simulators in surgical training. Traditionally, surgical training has encompassed years of apprenticeship whereby trainees would assist and perform surgical procedures under direct supervision from a senior. However, this method of training has seen to be high in terms of cost, time consuming and does not provide consistent effectiveness [1]. Traditional training methods also require skills to be practised upon a patient, with implications on patient safety. Although acknowledged that supervised clinical operative training does not affect patient outcome [2], simulated training avoids the ethical dilemma of performing new skills on a patient $[3,4]$.

As a profession we have learnt many lessons from the aviation industry. The World Health Organisation (WHO) surgical safety checklist used in surgical practice today was rolled out following examples from the checklists used by airlines for flight checks [5]. Other similarities with the airline industry include the use of simulation to practise high risk manoeuvres such as flying in poor weather conditions and military situations for instance, hostile flight surroundings. First proposed by Satava et al. in 1993 [6], simulation has since been introduced across many surgical specialties, offering the chance to develop operative skills in a harm-free environment.

There are five categories of technical simulators that are used in practice today:

\footnotetext{
* Address correspondence to this author at the Department of Plastic Surgery, Whiston Hospital, Liverpool, UK L35 5DR; x2028; Tel: + 44(0)1244366265; Fax: +44(0)1244366265; E-mail: hindocha2001@yahoo.com
} 
1. Bench models/ box trainers

2. Virtual reality

3. Human cadavers

4. Animals

5. Robotics

For many years the medical profession has used cadaveric material and animals to learn and practice skills. Many courses employ this material to teach simple tasks such as suturing to more complex tasks such as bowel anastomoses. Live animals may also be used, such as the use of anaesthetised rats for the teaching of microsurgical skills for plastic surgery trainees. Box trainers are used to provide basic laparoscopic skill. Bench models are most commonly used for practicing simple skills such as knot tying.

Advances in technology have led to an increase in high fidelity virtual reality simulators. The global simulation market was estimated at a value of \$790.1 million in 2012, with expected growth to reach \$1930.5 million by 2017 [7]. With technology developed from the videogame industry, designed to enhance hand-eye co-ordination and the ability to perform 3D skills using a 2D screen, has led to simulations mostly designed to advance skills in laparoscopic surgery [8]. Virtual reality training involves the use of a computer screen for graphic display of the organs to be operated upon. Tools can be used to provide haptic and tactile feedback for the trainee. Furthermore, data from imaging sequences such as CT or MRI can be inputted into software to replicate real patient situations and display anatomical anomalies or complications. It has even been proposed that those who have played regularly on videogames in the past display better operative skills and ability to use simulators than those with limited experience of videogames [9 - 11].

This paper outlines the necessity for technical simulation in surgical training, reviewing current research that supports its use and the role for simulated training both now and in the future.

\section{THE NEED FOR SIMULATED TEACHING IN SURGICAL TRAINING}

There are five key challenges identified in current surgical training with regards to operative skills:

1. Increasing popularity of minimally invasive procedures

2. Cost of training

3. Exposure

4. National focus on patient safety

5. Consultant practice

\section{Increasing Popularity of Minimally Invasive Procedures}

In recent years, the number of interventions performed as minimally invasive procedures has increased exponentially, including an increase in those done in an emergency setting [12]. Minimally invasive surgery demands specific technical skills that must be learnt and then practised in order to become technically proficient. Skills include accurate hand-eye co-ordination, a high level of manual dexterity, careful handling of tissues to account for loss of tactile feedback, and visualisation upon screens not capable of producing 3D images. With the expansion of these procedures into many subspecialties of surgery, both trainees and senior surgeons need to acquire new skills and learn new technologies [12]. There is growing evidence in the literature for the use of simulated training in the development of such skills.

\section{Cost of Training}

It is well documented that operative time increases as the grade of surgeon reduces [13 - 16]. This has implications on cost, whereby less patients can be operated on in an allotted time. There are implications on training, where cost, efficiency and time pressures lead to condensed operating exposure for a trainee in order to get more procedures done in a given time period e.g. a theatre session. Potential repercussions on patient safety are quoted, due to longer anaesthetic times for patients, principally used in more complex procedures. The aforementioned points incur significant costs to health systems. Bridges and Diamond calculated that each surgical trainee incurs a cost of approximately $\$ 12000$ a year [17]. Access to simulation training facilities allows trainees to advance their skills with repeated practice leading to 
reduced operating times when replicating these abilities in a patient setting.

More recently, there has been a trend towards increasing personal costs of surgical training alongside a limitation of study leave funds between National Health Service (NHS) trusts. Trainees are now graduating with significant debt and then face mandatory courses to progress in their career. Many have to fund much of their training through personal finance. This has been cited as a cause to discourage good trainees from applying to surgical specialties, particularly those from poorer backgrounds [18]. Surgical simulation access provides training to all trainees, which may be especially important in those who cannot afford multiple expensive courses.

\section{Training Exposure}

The European Working Time Directive (EWTD) is a European-wide instruction for limiting working hours to meet health and safety requirements [19]. Introduced in 2009, there has since been a reduction in duty hours for all surgeons and consequently caused concerns for many, as described by a General Medical Council report in 2011 [20]. The directive has seen difficulties in the management of rotas, with more emphasis on service provision and some rotas may not fully represent the genuine number of hours worked [21]. This has led to a substantial reduction in training opportunities for surgeons. With many appraisals dependent upon the attainment of specific numbers of procedures, particularly in higher surgical training Annual Review of Competence Progression (ARCP) reviews, and certainly for the achievement of the Certificate of Completion of Training (CCT), many trainees have been forced to take steps to protect their own training. Trainees may often seek operative exposure at weekends, on days off and whilst on annual leave. This has obvious implications on work-life balance, fatigue and health. There has also been concern that current training hours may not produce the calibre of consultant capable of specialising, particularly with more complex procedures [22]. Simulated training could help in the attainment of key skills, providing opportunity to practice skills when other exposure is not accessible.

\section{National Focus on Patient Safety and Consultant Practice}

The Francis Report has changed the future of the NHS forever. It has highlighted inadequacies within services that had resulted in patient safety concerns. This has led to a national focus on quality improvement and patient safety. More specifically, this has led to the publication of outcome data for specific surgical procedures that is accessible to the public. For trainees, there is concern that training opportunities will become even more difficult to negotiate. Previously, trainee operating has been associated with increased patient risk $[15,16]$. Consultants are likely to want to keep outcomes positive by performing procedures themselves, particularly for more complex interventions. Recently, there have been concerns that there is no initiative for a consultant to train, as status is very much concerned with outcome [22]. Simulated scenarios may increase patient safety by allowing skills to be learnt and practiced in a nonpatient environment, and may improve consultant trust in a trainee who has taken time to learn skills prior to a patient procedure.

\section{CURRENT EVIDENCE}

There is a growing base of research on the use of simulation training in surgical practice. Cochrane (2016) published data on outcomes from thirty randomly controlled trials (RCT) evaluating different modalities of simulation training approaches [23]. This suggested a reduced surgical time and increased accuracy in the use of laparoscopic instruments [23]. A previous Cochrane systematic review in 2009 supported that the use of simulated surgical training was highly effective after reviewing 23 trials [24]. The transfer of operative skills from a simulation laboratory into practice was assessed in an analysis by Sturm et al. from 10 RCTs and one observational study and found that trainees who had undergone simulation training did better in patient-based assessment [25]. The quality of RCTs analysed in these reviews however, were of poor quality, the outcome measures were largely varied and there have since been many other studies assessing simulation approaches.

More recently, several large scale reviews have provided increasing evidence that simulation is effective as a learning tool for operative skills. Table 1 summarises the evidence:

The current literature provides good evidence that simulation training improves both operative time and operative skill, particularly when compared with those who have had no other training intervention for the procedure. This has particular implications on cost, where a reduction in operative time leads to increased operative efficiency and a 
reduction in cost.

Although improvements can be seen in operative skills with all techniques, several studies have tried to identify which simulation modality provides the most effective results. Nagendren et al. found that virtual reality trainers provide a greater reduction in operative times and an increase in performance skill when compared with box trainers for laparoscopic skills [26]. Furthermore, Hamilton et al. found that skills learnt from virtual reality training are more transferable to an operating environment than box trainers [27]. This is in stark contrast to the review by Zendejas $e t$ al. who found comparisons between box training and virtual reality training in 21 studies highlighting no advantage of virtual reality over box training, with pooled results actually favouring box training in terms of satisfaction and time to learn skills $[28,29]$. There is also concern about the additional cost incurred in training using virtual reality.

Table 1. Current research in surgical simulation training.

\begin{tabular}{|c|c|c|c|c|c|c|}
\hline Systematic Review & $\begin{array}{l}\text { No of } \\
\text { trials }\end{array}$ & Trial type & Skill & Simulation type & Outcomes assessed & Result \\
\hline $\begin{array}{c}\text { Nagendren M et al. } 2013 \\
{[1]}\end{array}$ & 8 & 8 RCT's & Laparocopy & $\begin{array}{l}\text { Virtual reality vs no } \\
\text { simulation } \\
\text { Virtual reality vs box } \\
\text { training }\end{array}$ & $\begin{array}{l}\text { Operative time } \\
\text { Operative } \\
\text { performance }\end{array}$ & $\begin{array}{l}\text { Reduction in operative time } \\
\text { Increase in skill performance }\end{array}$ \\
\hline Thomas et al. 2013 [26] & 32 & $\begin{array}{l}21 \text { RCT's } \\
11 \text { Cohort } \\
\text { studies }\end{array}$ & Variable & $\begin{array}{c}\text { Box trainers } 9 \\
\text { Virtual reality } 14 \\
\text { Human cadaver } 4 \\
\text { Animal model } 2 \\
\text { Robotics } 3 \\
\end{array}$ & Task performance & $\begin{array}{l}\text { Improvement in skill } \\
\text { performance in all modalities }\end{array}$ \\
\hline Zendejas et al. 2013 [27] & 219 & $\begin{array}{l}91 \text { RCT's } \\
(48 \%)\end{array}$ & Laparoscopy & $\begin{array}{c}\text { All modalities: } \\
\text { Simulation vs no } \\
\text { intervention } 151 \\
\text { Simulation vs non- } \\
\text { stimulation intervention } 3 \\
\text { Comparison between } \\
\text { different simulation } \\
\text { modalities } 79\end{array}$ & $\begin{array}{c}\text { Knowledge } \\
\text { Patient effects } \\
\text { Operative time } \\
\text { Operative skill }\end{array}$ & $\begin{array}{c}\text { Improvement in skill } \\
\text { Improvement in operative } \\
\text { time } \\
\text { Improvement in knowledge } \\
\text { Improvement in patient effects }\end{array}$ \\
\hline Buckley et al. 2014 [28] & 16 & 16 RCT's & Laparoscopy & & $\begin{array}{l}\text { Operative times } \\
\text { Technical skills }\end{array}$ & $\begin{array}{c}\text { Operative time improved in all } \\
\text { studies } \\
\text { Skills improved in } 88 \% \text { of } \\
\text { studies }\end{array}$ \\
\hline
\end{tabular}

In the literature there is frequent reference to the fidelity of simulation, fidelity referring to the degree to which a particular model or simulator can reproduce a real-life situation [30]. High fidelity indicates a high degree of similarity, such as that achieved by virtual reality training, and it is proposed that this provides better transfer of skills to real life situations. However, Gallagher et al object that high fidelity simulators used without supervision from adequate trainers would merely inform a trainee what to do and in what order, rather than provide accurate and timely feedback on performance errors [31]. This implies that it is actually the level of supervision that reflects the degree of skill acquisition rather than the type of simulator used.

Regarding the transfer of skills from the simulator to the patient, Thomas et al. found that all but the animal models were transferrable to an operative setting [32]. Buckley et al. however have raised concerns that more objective measures of transferability need to be produced in order to make this statement more objective [28].

\section{SIMULATION'S ROLE IN SURGICAL TRAINING}

Increasing evidence for the use of simulation in surgical training means there have been many recent advances for the incorporation of simulation into teaching.

In early 2014, a new open access peer reviewed journal was released aiming to enhance surgical training and patient safety [31]. The committee encourages the widespread development of simulation facilities and courses within deaneries to provide methods for the acquisition and maintenance of surgical skills. They provide expertise and can assist in the development of new simulation centres throughout the United Kingdom.

The Association of Surgeons in Training (ASiT) fully endorses the incorporation of simulation into surgical training. A recent survey by ASiT found that trainees were enthused by the idea of access to simulation facilities and felt that regular simulation training would increase operative confidence [33]. 
The Intercollegiate Surgical Curriculum Programme (ISCP) is presently used by all surgical trainees and has incorporated simulation into their performance-based assessments within some surgical fields. A report by the Joint Committee of Surgical Training (JCST) chairman in 2013 stated that simulation can accelerate training and improve patient safety and will continue to be rolled out into curriculae [34]. Trainees have diverse learning curves, any may require a different number of repetitions of a procedure in order to be deemed competent [35]. Simulation may help to flatten this learning curve. There are concerns by the JCST as to the added expense of providing such simulation facilities in each deanery. A recent cost-effectiveness study however, has found that simulation training for surgeons is financially viable by reducing training time and increasing efficiency [36]. There is, at present, much variance across the surgical deaneries and a national approach would be developed in order to provide consistency.

\section{PITFALLS}

Concerns have been raised about the introduction of simulation into the training of surgeons. A review by Kneebone and Aggarwal in 2009 felt that simulation may not adequately prepare a trainee for a patient experience due to the lack of accountability for abnormal anatomy, the unknown, stressful circumstances and bad working environments [37]. They advocated that simulation should be used as an aide, and that perhaps trainees could "warm up" using an advanced simulator before a procedure, where patients' imaging are incorporated into the software [37]. Although evidence for simulation training is strong, it may not be appropriate to extrapolate results across all specialties, as most studies reviewed focus upon laparoscopic skills used in general surgery, urology and gynaecology. For specialties requiring other skills, such as microsurgery used in plastic and orthopaedic procedures, more research is needed on the implementation and effectiveness of simulation models.

It is not only technical skills that affect a patient experience. Human factors also affect the patient pathway, and simulation programmes should include non-technical training such as team-working, stress management and coping strategies to help deal with the working environment [38].

There is some trepidation regarding access to simulation facilities across deaneries. As simulated teaching is increasingly being used for training purposes, there should be a standard for each deanery to achieve in reference to both facilities and training. This will most likely require dedicated trainers in allocated teaching sessions as well as accessibility out of hours. Grantcharov et al. highlight the importance of robust educational frameworks for the implementation and success of simulation for technical skills [39].

\section{CONCLUSION}

With an increasing multitude of literature supporting its use, it is clear that there is a significant role for simulation in surgical training. With an increasing focus on patient safety, technological advances in surgical technique, and continued concerns about trainee exposure to operative procedures, there is very much a need for simulation in training. The recent incorporation of simulation into training curricula should promote consistency in access to simulation facilities across deaneries and invite the experience of dedicated trainers to optimise educational use.

\section{CONFLICT OF INTEREST}

The authors confirm that this article content has no conflict of interest.

\section{ACKNOWLEDGEMENTS}

Declared none.

\section{REFERENCES}

[1] Nagendran M, Gurusamy KS, Aggarwal R, Loizidou M, Davidson BR. Virtual reality training for surgical trainees in laparoscopic surgery. Cochrane Database Syst Rev 2013; (8): CD006575. [Review]. [PMID: 23980026]

[2] Kanakala V, Bawa S, Gallagher P, et al. Outcome of patients in laparoscopic training courses compared to standard patients. The Surgeon. J R Coll Edinburgh Irel 2010; 8(3): 132-5. [http://dx.doi.org/10.1016/j.surge.2009.10.030]

[3] Reznick RK, MacRae H. Teaching surgical skillschanges in the wind. N Engl J Med 2006; 355(25): 2664-9. [http://dx.doi.org/10.1056/NEJMra054785] [PMID: 17182991]

[4] Moorthy K, Munz Y, Jiwanji M, Bann S, Chang A, Darzi A. Validity and reliability of a virtual reality upper gastrointestinal simulator and cross validation using structured assessment of individual performance with video playback. Surg Endosc 2004; 18(2): 328-33. 
[http://dx.doi.org/10.1007/s00464-003-8513-2] [PMID: 14691708]

[5] Human Factors, OSD, Safety Regulation Group, Civil Aviation Authority Society UK, Aviation Maintenance Human Factors. 37 Windsor Street, Cheltenham, Glos, GL52 2DG: Documedia Solutions Ltd. 2002.

[6] Satava RM. Virtual reality surgical simulator. The first steps. Surg Endosc 1993; 7(3): 203-5. [http://dx.doi.org/10.1007/BF00594110] [PMID: 8503081]

[7] Rohan. Healthcare/Medical Simulation Market. Available from: http://www.prweb.com/releases/healthcare-medical-simula/market/ prweb11585222.htm 2014. Marketsandmarkets. [Accessed 15 Feb]

[8] Rosenberg BH, Landsittel D, Averch TD. Can video games be used to predict or improve laparoscopic skills? J Endourol 2005; 19(3): 372-6. [http://dx.doi.org/10.1089/end.2005.19.372] [PMID: 15865530]

[9] van Dongen KW, Verleisdonk EJ, Schijven MP, Broeders IA. Will the Playstation generation become better endoscopic surgeons? Surg Endosc 2011; 25(7): 2275-80.

[http://dx.doi.org/10.1007/s00464-010-1548-2] [PMID: 21416186]

[10] Roser Jc Jr, Lynch PJ, Cuddihy L, Gentile DA, Klonsky J, Merrell R. The impact of video games on training surgeons in the $21^{\text {st }}$ century. Arch Surg 2007; 142(2): 181-6.

[11] Grantcharov TP, Bardram L, Funch-Jensen P, Rosenberg J. Learning curves and impact of previous operative experience on performance on a virtual reality simulator test laparoscopic surgical skills. Am J Surg 2003; 185(2): 146-9.

[12] Ulmer BC. Best practices for minimally invasive procedures. AORN J 2010; 91(5): 558-72. [http://dx.doi.org/10.1016/j.aorn.2009.12.028] [PMID: 20450998]

[13] Farnworth LR, Lemay DE, Wooldridge T, et al. A comparison of operative times in arthroscopic ACL reconstruction between orthopaedic faculty and residents: the financial impact of orthopaedic surgical training in the operating room. Iowa Orthop J 2001; 21: 31-5. [PMID: 11813948]

[14] Babineau TJ, Becker J, Gibbons G, et al. The cost of operative training for surgical residents. Arch Surg 2004; 139(4): 366-9. [http://dx.doi.org/10.1001/archsurg.139.4.366] [PMID: 15078701]

[15] Kauvar DS, Braswell A, Brown BD, Harnisch M. Influence of resident and attending surgeon seniority on operative performance in laparoscopic cholecystectomy. J Surg Res 2006; 132(2): 159-63. [http://dx.doi.org/10.1016/j.jss.2005.11.578] [PMID: 16412471]

[16] Wilkiemeyer M, Pappas TN, Giobbie-Hurder A, Itani KM, Jonasson O, Neumayer LA. Does resident post graduate year influence the outcomes of inguinal hernia repair? Ann Surg 2005; 241(6): 879-82. [http://dx.doi.org/10.1097/01.sla.0000164076.82559.72] [PMID: 15912037]

[17] Bridges M, Diamond DL. The financial impact of teaching surgical residents in the operating room. Am J Surg 1999; 177(1): $28-32$. [http://dx.doi.org/10.1016/S0002-9610(98)00289-X] [PMID: 10037304]

[18] The Association of Surgeons in Training. The Cost of Surgical Training. Position Statement by the Association of Surgeons in Training 2007.

[19] Directive 2003/99/EC of the European Parliament and the Council of 4 November 2003 concerning certain aspects of the organisation of working time. Official Journal L 299, 18/11/2003. P. 0009-0019

[20] Ipsos MO. The impact of the implementation of the European Working Time Directive (EWTD); a qualitative research prepared for the General Medical Council. London: GMC 2011.

[21] Tait MJ, Fellows GA, Pushpananthan S, Sergides Y, Papadopoulos MC, Bell BA. Current neurosurgical trainees perception of the European Working Time Directive and shift work. Br J Neurosurg 2008; 22(1): 28-31. [http://dx.doi.org/10.1080/02688690701765532] [PMID: 18224519]

[22] Chikwe J, de Souza AC, Pepper JR. No time to train the surgeons. BMJ 2004; 328(7437): 418-9. [http://dx.doi.org/10.1136/bmj.328.7437.418] [PMID: 14976074]

[23] Sutherland LM, Middleton PF, Anthony A, et al. Surgical simulation: a systematic review. Ann Surg 2006; 243(3): 291-300. [http://dx.doi.org/10.1097/01.sla.0000200839.93965.26] [PMID: 16495690]

[24] Gurusamy KS, Aggarwal R, Palanivelu L, Davidson BR. Virtual reality training for surgical trainees in laparoscopic surgery. Cochrane Database Syst Rev 2009; (1): CD006575. [PMID: 19160288]

[25] Sturm LP, Windsor JA, Cosman PH, Cregan P, Hewett PJ, Maddern GJ. A systematic review of skills transfer after surgical simulation training. Ann Surg 2008; 248(2): 166-79. [http://dx.doi.org/10.1097/SLA.0b013e318176bf24] [PMID: 18650625]

[26] Thomas MP. The role of simulation in the development of technical competence during surgical training: A literature review. Int J Med Educ 2013; 4: 48-58. [http://dx.doi.org/10.5116/ijme.513b.2df7]

[27] Zendejas B, Brydges R, Hamstra SJ, Cook DA. State of the evidence on simulation-based training for laparoscopic surgery: a systematic review. Ann Surg 2013; 257(4): 586-93.

[http://dx.doi.org/10.1097/SLA.0b013e318288c40b] [PMID: 23407298] 
[28] Buckley CE, Kavanagh DO, Traynor O, Neary PC. Is the skillset obtained in surgical simulation transferable to the operating theatre? Am J Surg 2014; 207(1): 146-57. [http://dx.doi.org/10.1016/j.amjsurg.2013.06.017] [PMID: 24238602]

[29] Hamilton EC, Scott DJ, Fleming JB, et al. Comparison of video trainer and virtual reality training systems on acquisition of laparoscopic skills. Surg Endosc 2002; 16(3): 406-11. [http://dx.doi.org/10.1007/s00464-001-8149-z] [PMID: 11928017]

[30] Hays R, Singer M. Simulation fidelity in training system design: Bridging the gap between reality and training. Springer-Verlag 1989. [http://dx.doi.org/10.1007/978-1-4612-3564-4]

[31] Gallagher AG, O'Sullivan GC. Fundamentals of Surgical Simulation: Principles and Practices. In: Chapter 11; Simulation in and for medicine: Where next?. London: Springer-Verlag 2012.

[32] About Journal. Journal of Surgical Simulation. Available from: http://www.journalsurgicalsimulation.com/journal-surgical-simulation-uk 2014. [Accessed $25 \mathrm{Feb}]$

[33] Milburn JA, Khera G, Hornby ST, Malone PS, Fitzgerald JE. Introduction, availability and role of simulation in surgical education and training: review of current evidence and recommendations from the Association of Surgeons in Training. Int J Surg 2012; 10(8): 393-8. [http://dx.doi.org/10.1016/j.ijsu.2012.05.005] [PMID: 22609475]

[34] Joint Committee on Surgical Training. JCST Newsletter July 2013 Chairman's Update. Available from: http://www.jcst.org/ docs/jcst_newsletter 2014. 2013 [Accessed Feb]

[35] Brunner WC, Korndorffer JR Jr, Sierra R, et al. Laparoscopic virtual reality training: are 30 repetitions enough? J Surg Res 2004; 122(2): $150-6$. [http://dx.doi.org/10.1016/j.jss.2004.08.006] [PMID: 15555611]

[36] Stefanidis D, Hope WW, Korndorffer JR Jr, Markley S, Scott DJ. Initial laparoscopic basic skills training shortens the learning curve of laparoscopic suturing and is cost-effective. J Am Coll Surg 2010; 210(4): 436-40.

[http://dx.doi.org/10.1016/j.jamcollsurg.2009.12.015] [PMID: 20347735]

[37] Kneebone R, Aggarwal R. Surgical training using simulation. BMJ 2009; 338: b1001. [http://dx.doi.org/10.1136/bmj.b1001] [PMID: 19443913]

[38] Patel H, Joseph J. Simulation training in laparoscopy and robotic surgery. London: Springer-Verlag 2012; p. 13. [http://dx.doi.org/10.1007/978-1-4471-2930-1]

[39] Grantcharov TP, Reznick RK. Teaching procedural skills. BMJ 2008; 336(7653): 1129-31. [http://dx.doi.org/10.1136/bmj.39517.686956.47] [PMID: 18483056]

(C) Snashall et al.; Licensee Bentham Open

This is an open access article licensed under the terms of the Creative Commons Attribution-Non-Commercial 4.0 International Public License (CC BY-NC 4.0) (https://creativecommons.org/licenses/by-nc/4.0/legalcode), which permits unrestricted, non-commercial use, distribution and reproduction in any medium, provided the work is properly cited. 